\title{
Sexual Dimorphism of the Human Cerebral Pallium
}

\author{
By \\ Jun GOTO and Noboru GOTO \\ Department of Anatomy, Showa University School of Medicine, 5-8, Hatanodai 1, Shinagawa-ku, Tokyo 142-8555, \\ Japan \\ - Received for Publication, November 30, 1999 \\ Key Words: Anatomy, Brain volume, Cortico-medullary ratio, Gender difference, Morphometry

\begin{abstract}
Summary: Sexual dimorphism was found regarding the cortico-medullary volume ratio in human brains throughout the age range, without the need for statistical analysis. After measurement of the areas of the whole pallium, cerebral cortex and cerebral medullary substance in $10 \mathrm{~mm}$ thick slices with the help of an image-analyzer, the total volume of the brain was calculated by integrating the volumes of each slice. The sexual dimorphism found in the cortico-medullary volume ratio may be of importance to understand sex differences, to solve questions related to various activities, functions, behaviours and responses, or to evaluate various pathologic conditions including non-physiological cerebral atrophy.
\end{abstract}

Research on the sex differences in the brain has long been an interesting and important subject in the field of neurosciences. The results, however, are mainly derived from experimental work or medical imaging examination, and are rather limited as far as the actual human brain is concerned: Sylvian fissure asymmetry ${ }^{17)}$, sylvian fissure and corpus callosum $^{2)}$, corpus callosum ${ }^{15)}$, cerebral cortex ${ }^{13)}$ and striate cortex ${ }^{10}$. We have obtained new data regarding the sex difference of the cortico-medullary volume ratio, or in other words, the grey matter/ white matter volume ratio of the cerebral pallium in the human brain. A description follows.

\section{Material and Methods}

For the study of volumetry and cortico-medullary volume ratio, we collected 18 Japanese autopsy brains (11 males and 7 females) without any neurological diseases or pathological autopsy findings except for physiological ageing changes. Their ages ranged from 19 to 82 years for males and from 12 to 85 years for females. The patients had all died instantly, with a sudden onset of acute coronary failure, myocardial infarct, traumatic rupture of the liver or ruptured aortic aneurysm. Within six hours, the brain was removed from the cranial cavity for fixation in a $3.7 \%$ solution of formaldehyde with initial hand treatment in order to allow it to float in the solution for 10 minutes. This was to keep the shape as much as possible as it was in the cranial cavity. The solution was changed to a fresh one within one hour. The brain was kept in it on a bed of thick cotton for more than 7 days. Then, it was sliced serially at $10 \mathrm{~mm}$ thickness. A photocopy of each section was taken with a copying machine (Xerox) at $100 \%$ size and in picture mode. The outline of the pallium, the cerebral cortex and the cerebral medullary substance was traced in every photocopy to measure the area with the use of an image-analyzer (Kontron-Carl Zeiss). The volumes of the cerebral pallium, cortex and medullary substance were calculated separately by integrating all slices. The cortico-medullary volume ratio of the pallium was calculated for every brain.

\section{Results}

The data are listed in Table 1 , together with analysis conducted using Wilcoxon rank-sum test. The volumes of the bilateral pallia ranged from 796.8 to $1143.2 \mathrm{~cm}^{3}$ in the males, and from 658.1 to $939.7 \mathrm{~cm}^{3}$ in the females, the volumes of bilateral cerebral medullary substance from 318.5 to

Correspondence should be addressed to Noboru Goto, Showa Univ. Sch. of Med.; e-mail: goto@med.showa-u.ac.jp 
Table 1. Volume data and cortico-medullary volume ratios (CMVR) of the human pallium, with Wilcoxon ranksum testing

\begin{tabular}{lccccc}
\hline Sex & Age & Pallium* & Medullary* & Cortex* & CMVR \\
\hline Female & & & & & \\
& 56 & 658.1 & 366.1 & 292.0 & 0.798 \\
& 13 & 693.0 & 378.9 & 314.1 & 0.829 \\
& 31 & 899.0 & 470.5 & 428.5 & 0.911 \\
& 85 & 939.7 & 467.9 & 471.8 & 1.008 \\
& 12 & 796.5 & 378.6 & 417.9 & 1.104 \\
& 46 & 899.4 & 392.8 & 499.6 & 1.272 \\
Male & 30 & 816.0 & 356.7 & 459.4 & 1.288 \\
& & & & & \\
& 70 & 848.2 & 364.3 & 483.9 & 1.328 \\
& 77 & 796.8 & 341.8 & 455.0 & 1.331 \\
& 50 & 1066.9 & 445.6 & 621.3 & 1.394 \\
& 63 & 1062.3 & 439.1 & 623.2 & 1.419 \\
& 19 & 1143.2 & 468.0 & 675.2 & 1.443 \\
& 54 & 851.8 & 348.1 & 503.7 & 1.447 \\
& 65 & 818.1 & 333.9 & 484.2 & 1.450 \\
& 69 & 866.0 & 350.1 & 515.9 & 1.474 \\
& 64 & 898.0 & 354.9 & 543.1 & 1.530 \\
& 82 & 936.5 & 364.2 & 572.3 & 1.571 \\
& 21 & 875.2 & 318.5 & 556.7 & 1.748 \\
\hline
\end{tabular}

Statistics of 7

female brains

Rank-sum

Rank-sum $-28^{\dagger} \quad 23$

105 - Rank-sum ${ }^{\ddagger}$

* Bilateral data in $\mathrm{cm}^{3}$.

${ }^{\dagger}$ Minimum rank-sum: $1+2+3+4+5+6+7=28$.

$\ddagger$ Maximum rank-sum: $12+13+14+15+16+17+18=105$.

$\S$ Not necessary for statistical analysis.

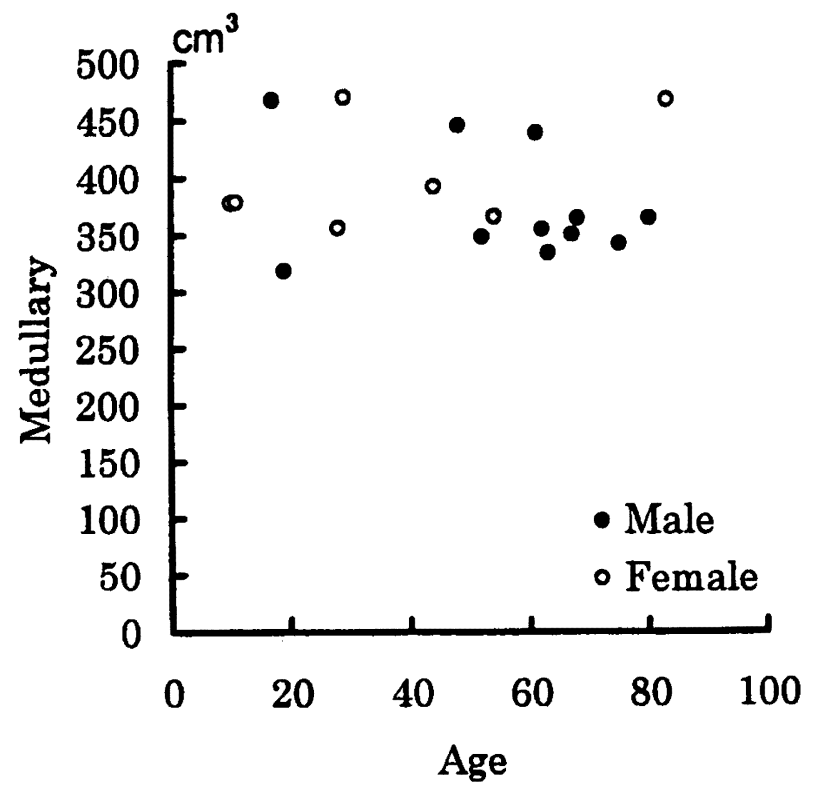

$105-$ Rank-sum of 7 female brains $=18$

Fig. 1. Scatter diagram of the human cerebral medullary substance volume (in 18 autopsy brains).
$468.0 \mathrm{~cm}^{3}$ in the males, and from 356.7 to $470.5 \mathrm{~cm}^{3}$ in the females. This shows only slight difference between the two sexes (Fig. 1). However, the volumes of bilateral cerebral cortices ranged from 455.0 to $675.2 \mathrm{~cm}^{3}$ in the males, and from 292.0 to $499.6 \mathrm{~cm}^{3}$ in the females. Here we have an obvious

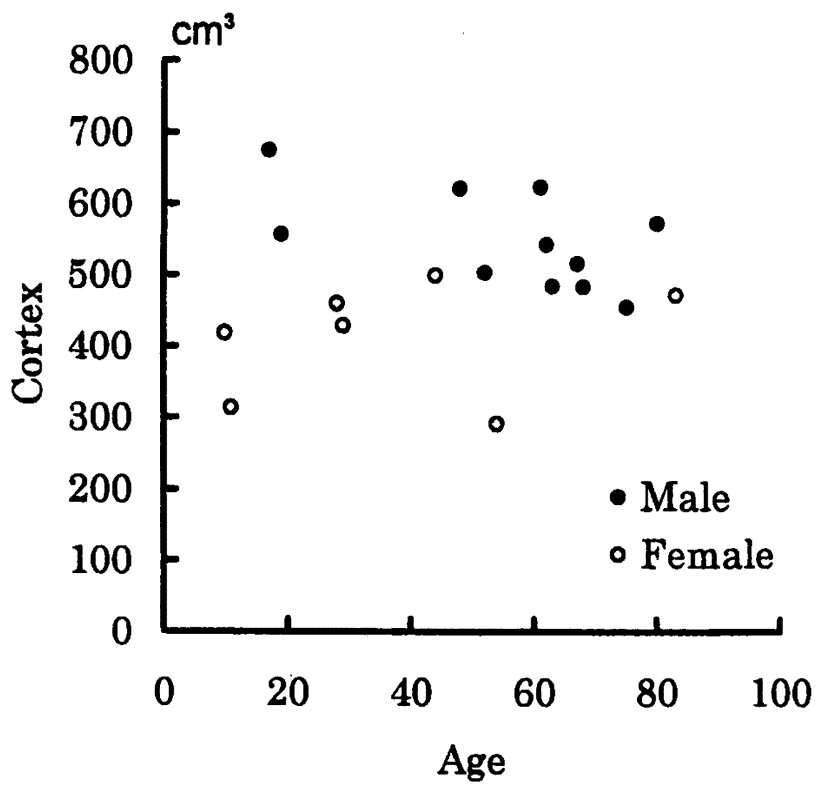

Rank-sum of 7 female brains $-28=5$

Fig. 2. Scatter diagram of the human cerebral cortex volume (in 18 autopsy brains).

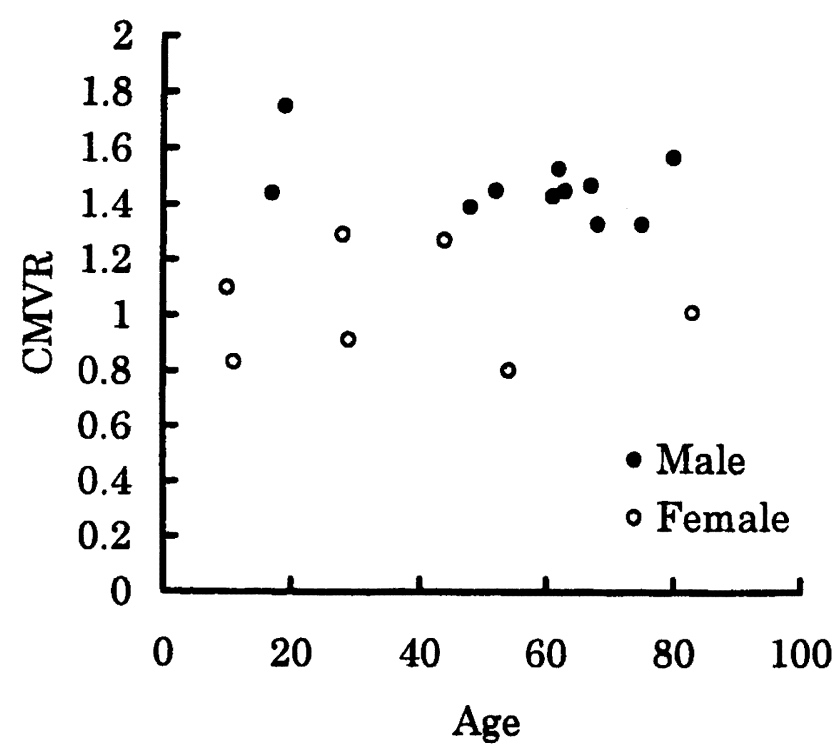

Rank-sum of 7 female brains $-28=0$
Fig. 3. Sexual dimorphism in cortico-medullary volume ratios (CMVR) of the human pallium (in 18 autopsy brains). 
difference between the two sexes (Fig. 2). When we calculate the cortico-medullary volume ratios, we find that they range from 1.328 to 1.748 in the males, and from 0.798 to 1.288 in the females. In this case, the difference between the two sexes is obvious, and does not require confirmation by statistical analysis (Fig. 3). This difference is mainly due to the larger quantity of the cerebral cortex in the males (Figs. 1 and 2).

\section{Discussion}

Research on the sex differences in the brain has been conducted for more than a quarter of a century. Reports have mainly dealt with animal brains, or with human neuroimages ${ }^{3,4,6,7,8,9,11,14)}$. Research on the sex differences in the developed cerebral pallium of the human brains, however, is rather limited. Some articles have reported on neuronal numbers and densities in cortices ${ }^{12,13,16)}$, others on the geometry of the corpus callosum or the anterior commissure ${ }^{1,5)}$. But no article, so far, has dealt with cerebral cortico-medullary ratios. Our report reveals for the first time the complete sexual dimorphism of the human cerebral pallium on the basis of anatomical morphometry. It may, therefore, be fundamentally important not only for clinical diagnosis, but also for the understanding of sex differences in various activities, functions, behaviours and responses, or in order to bring various unsolved questions to light.

\section{Acknowledgement}

The authors would like to thank Prof. Akira Okada, of Osaka City University, for computer programming, and Ms. Setsuko Kitajima for secretarial assistance.

\section{References}

1) Allen LS and Gorski RA. Sexual orientation and the size of the anterior commissure in the human brain. Proc Natl Acad Sci 1992; 89:7199-7202.

2) Aboitiz F, Scheibel AB and Zaidel E. Morphometry of the sylvian fissure and the corpus callosum, with emphasis on sex differences. Brain 1992; 115:1521-1541.

3) Byne W, Bleier R and Houston L. Variation in human corpus callosum do not predict gender: $A$ study using magnetic resonance imaging. Behav Neurosci 1988; 102:222-227.

4) Cowell PE, Turetsky BI, Gur RC, Grossman RI, Shtasel DL and Gur RE. Sex differences in aging of the human frontal and temporal lobes. J Neurosci 1994; 14:4748-4755.

5) de Lacoste-Utamsing C and Holloway RL. Sexual dimorphism in the human corpus callosum. Science 1982; 216:1431-1432.

6) Grant R, Condon B, Lawrence A, Hadley DM, Patterson J, Bone I and Teasdale GM. Human cranial CSF volumes measured by MRI: Sex and age Influences. Magn Reson Imaging 1987; 5:465-468.

7) Gur RC, Mozley PD, Resnick SM, Gottlieb GL, Zimmerman R, Herman G, Atlas S. Grossman R, Berretta D, Erwin $R$ and Gur RE. Gender differences in age effect on brain atrophy measured by magnetic resonance imaging. Proc Natl Acad Sci USA 1991; 88:2845-2849.

8) Guttmann CRG, Jolesz FA, Kikinis R, Killiany RJ, Moss $\mathrm{MB}$, Sandor T and Albert MS. White matter changes with normal aging. Neurology 1998; 50:972-978.

9) Gyldensted C and Kosteljanetz M. Measurement of the normal ventricular system with computer tomography of the brain: A preliminary study on 44 adults. Neuroradiol 1976; 10:205-213.

10) Murphy Jr GM. Volumetric asymmetry in the human striate cortex. Exp Neurol 1985; 88:288-302.

11) Murphy DGM, DeCarli C, McIntossh AR, Daly E, Mentis MJ, Pietrini P, Szczzepanik J, Schapiro MB, Grady CL, Horwitz B and Rapoport SI. Sex differences in human brain morphometry and metabolism: An in vivo quantitative magnetic resonance imaging and positron emission tomography study on the effect of aging. Arch Gen Psychiatry 1996; 53:585-594.

12) Pakkenberg B, Gundersen HJG. Neocortical neuron number in the humans: Effect of sex and age. J Comp Neurol 1997; 384:312-320.

13) Rabinowicz $T$, Dean DE, McDonald-Comber Petetot $J$ and de Courten-Myers GM. Gender differences in the human cerebral cortex: More neurons in males; More processes in females. J Child Neurol 1999; 14:98-107.

14) Shaywitz BA, Shaywitz SE, Pugh KR, Constable RT, Skudlarski P, Fulbright RK, Bronen RA, Fletcher JM, Shankweller DP, Katz L and Gore JC. Sex differences in the functional organization of the brain for language. Nature 1995; 373:607-609.

15) Steinmetz H, Staiger JF, Schlaug G, Huang YX and Jöncke $\mathrm{L}$. Corpus callosum and brain volume in women and men. NeuroReport 1995; 6:1002-1004.

16) Witelson SF, Glezer II and Kigar DL. Women have greater density of neurons in posterior temporal cortex. J Neurosci 1995; 15:3418-3428.

17). Witelson SF and Kigar DL. Sylvian fissure morphology and asymmetry in men and women: Bilateral differences in relation to handedness in men. J Comp Neurol 1992; 323:326-340. 